\title{
Does sex affect second $A C L$ injury risk? A systematic review with meta-analysis
}

\author{
Akash D Patel (D) ,' Garrett S Bullock (D) , ${ }^{2}$ Jordan Wrigley, ${ }^{3}$ Mark V Paterno, ${ }^{4,5}$ \\ Timothy C Sell, ${ }^{6}$ Justin M Losciale (1) ${ }^{7,8}$
}

\begin{abstract}
- Additional supplemental material is published online only. To view, please visit the journal online (http://dx.doi. org/10.1136/bjsports-2020103408).
\end{abstract}

\section{'Duke University School of} Medicine, Durham, North Carolina, USA

${ }^{2}$ Nuffield Department of Orthopaedics, Rheumatology, and Musculoskeletal Sciences, University of Oxford, Oxford, UK ${ }^{3}$ Duke University Medical Center, Durham, North Carolina, USA

${ }^{4}$ Division of Occupational Therapy and Physical Therapy, Division of Sports Medicine, Cincinnati Children's Hospital, Cincinnati, Ohio, USA

${ }^{5}$ Department of Pediatrics, University of Cincinnati College of Medicine, Cincinnati, Ohio, USA

${ }^{6}$ Atrium Health Musculoskeletal Institute, Charlotte, North

Carolina, USA

${ }^{7}$ Faculty of Medicine, Department of Physical Therapy, The University of British Columbia, Vancouver, British Columbia, Canada ${ }^{8}$ Arthritis Research Canada, Vancouver, British Columbia, Canada

\section{Correspondence to} Dr Justin M Losciale, The University of British Columbia, Vancouver, BC V6T 1Z4, Canada;

jlosciale8@outlook.com

Accepted 1 May 2021 Published Online First 17 May 2021

\author{
ABSTRACT \\ Objective To determine sex-based differences in \\ risk of a second ACL injury (overall and by laterality) \\ following primary $\mathrm{ACL}$ reconstruction in athletes who are \\ attempting to return to sport.
}

Design Systematic review with meta-analysis.

Data sources Systematic search of five databases conducted in August 2019.

Eligibility criteria for selecting studies Studies reporting sex-based differences in the incidence of second ACL injury in athletes attempting to returnto-sports and who were followed for at least 1 year following primary $\mathrm{ACL}$ reconstruction.

Results Nineteen studies were included in this review, with seven studies excluded from the primary metaanalysis due to high risk of bias. The remaining 12 studies ( $n=1431$ females, $n=1513$ males) underwent meta-analysis, with all 19 studies included in a sensitivity analysis. Total second $\mathrm{ACL}$ injury risk was $21.9 \%$ (females: $22.8 \%$, males: $20.3 \%$ ). Females were found to have $10.7 \%$ risk of an ipsilateral ACL injury and $11.8 \%$ risk of a contralateral $A C L$ injury. Males were found to have $12.0 \%$ risk of an ipsilateral $A C L$ injury and $8.7 \%$ risk of a contralateral $A C L$ injury. No statistically significant differences were observed for total second $\mathrm{ACL}$ injury risk (risk difference $=-0.6 \%, 95 \% \mathrm{Cl}-4.9$ to $3.7, p=0.783, I^{2}=41 \%$ ) or contralateral $A C L$ injury risk (risk difference $=1.9 \%, 95 \% \mathrm{Cl}-0.5 \%$ to $4.4 \%$, $p=0.113, l^{2}=15 \%$ ) between sexes. Females were found to have a $3.4 \%$ absolute risk reduction in subsequent ipsilateral $\mathrm{ACL}$ injury risk compared with males (risk difference $=-3.4 \%, 95 \% \mathrm{Cl}-6.7 \%$ to $-0.02 \%$, $p=0.037, I^{2}=35 \%$ ).

Conclusion Both sexes have $>20 \%$ increased risk of experiencing a second $\mathrm{ACL}$ injury. Any difference in the absolute risk of either a subsequent ipsilateral or contralateral ACL injury between sexes appears to be small.

Registration PROSPERO (CRD42020148369)

\section{INTRODUCTION}

Female athletes are at two to four times greater risk of primary ACL injury compared with males, even when controlling for sport and competition level. ${ }^{1-5}$ This difference has been attributed to anatomy, hormonal effects, neuromuscular control, biomechanics and sport participation. ${ }^{6-19}$ Understanding the underlying risk factors and differences between sex has led to successful development of primary prevention programmes that have shown the ability to reduce the risk of sustaining an ACL injury by half in all athletes, with a decrease of non-contact ACL injuries in females by two-thirds. ${ }^{20}$ These programmes are pivotal to the long-term health of athletes in reducing the risk of the initial ACL injury and in mitigating the risk of future complications associated with the injury, such as obesity, physical inactivity and osteoarthritis. ${ }^{21-23}$ Unfortunately, not all athletes will be protected from a primary ACL injury, often requiring ACL reconstruction as part of the treatment plan. Following surgical reconstruction and rehabilitation, athletes expect to return to sport at their prior level. ${ }^{24}$ Although returning to sport enhances the quality of life in athletes, ${ }^{25}$ it does expose them to the possibility of a second ACL injury, ${ }^{26} 27$ with $21 \%-23 \%$ of athletes experiencing either a re-tear of the ipsilateral graft or a new ACL injury to the contralateral knee. ${ }^{28-30}$

Age has been reported to be a risk factor for second ACL injury, ${ }^{28}$ 31-34 with athletes younger than 25 years old experiencing a combined second ACL injury risk of $23 \% .^{28}$ Risk factors for second ACL injury also include allograft usage and lower self-reported confidence or psychological readiness. ${ }^{33} 3536$ However, the relationship between sex and second ACL injury risk is less clear. One study reports that female athletes have a greater second ACL injury risk in both knees compared with males. ${ }^{29}$ Another study suggests that differences in risk of a second ACL injury are significantly higher in females when comparing contralateral ACL injuries $($ female $=23.7 \%$; male $=10.5 \%$ ), but no differences in ipsilateral ACL re-tear risk (female $=8.5 \%$; male $=10.5 \%) .{ }^{30}$ Other studies have found no sex differences. $^{3738}$

Understanding risk factors regarding second ACL injury is vital to the health and well-being of athletes. When compared with primary ACL injury and reconstruction, second ACL injury and reconstruction are associated with an increased likelihood of meniscal damage, reduced thigh muscle explosiveness and strength, increased pain, higher risk of post-traumatic knee osteoarthritis and future physical inactivity. ${ }^{39-41}$ Similar to primary ACL injury, reducing the risk of second ACL injuries requires understanding if sex is a risk factor. The lack of consensus on which sex is most at risk for a second ACL injury may inhibit the rigorous development of effective second ACL injury screening and prevention programmes.

The purpose of this systematic review was to (1) determine the second ACL injury risk for patients included in studies followed for at least 12 months following their primary ACL reconstruction, (2) investigate the sex-based differences in risk of a second ACL injury following primary ACL reconstruction in active individuals attempting to 
return-to-sport, (3) determine the risk between sex and localisation of the second ACL injury (ipsilateral graft tear vs native contralateral ACL injury), and (4) determine if cohort age, percentage of cohort who return-to-sport, and pre-injury activity levels are moderators of the differences observed between male and female second ACL injury risk. We hypothesise that female athletes will demonstrate a higher second ACL injury risk compared with males, that female athletes will have a higher risk of contralateral ACL injuries compared with males and that younger age $(<18$ years) will modify sex-based differences in second ACL injury risk.

\section{METHODS}

Protocol, registration and critical appraisal

This systematic review and meta-analysis followed the Preferred Reporting Items for Systemic Reviews and Meta-Analyses (PRISMA) guidelines. ${ }^{42} 43$ The web-based platform for systematic review production, Covidence (Veritas Health Innovation), was used to manage all stages of the review process. AMSTAR 2 (A Measurement Tool to Assess Systematic Reviews, version 2) was used to critically appraise this review. ${ }^{44}$

\section{Literature search}

A medical research librarian (JW) conducted a computerised literature search using a combination of keywords and database-specific controlled terminology related to 'ACL injuries', 'ACL surgeries' and 're-injury' in the following databases: MEDLINE via PubMed, Embase (Elsevier), CINAHL (EBSCO), SPORTDiscus (EBSCO) and Scopus (Elsevier). The search was conducted on 22 August 2019 and was not limited by date. Editorials and comments were removed as were animal-only studies. Results from all databases $(n=3932)$ were uploaded to Covidence for screening. Following completion of full-text screening, a manual search of citation lists from included studies was performed to identify relevant citations that were missed, and a query of prominent journals related to sports medicine and orthopaedics was performed to capture citations published following the completion of the systematic search. A detailed search strategy can be found in online supplemental appendix 1 .

\section{Inclusion and exclusion criteria}

Articles were included in this systematic review if they met the following criteria: (1) study cohort's average age was between 10 and 50 years; (2) undergoing any graft type ACL reconstruction; (3) attempting to return to sport, with a pre-injury or post-injury Tegner activity level of $\geq 7$; (4) study reported second ACL injury incidence (ipsilateral graft rupture, native contralateral ACL injury or both); (5) ACL injuries were stratified by sex (or data were made available by authors); (6) study follow-up was at least 1 year following ACL reconstruction. Due to many studies not reporting activity levels using the Tegner scale, we used available information to determine equivalent activity levels appropriate for our cut-off including Marx activity score $\geq 8$, International Knee Documentation Committee (IKDC) Level 1 or 2 sport determination, or descriptive information indicating Tegner $\geq 7$. In addition, to ensure the majority of study participants were attempting to return-to-sport, we established that $55 \%$ of the entire sample must return-to-sport for the study to be included. This threshold was chosen based on previous work demonstrating $55 \%$ of athletes return to a competitive sport. ${ }^{26}$

Articles were excluded if (1) study participants had a prior knee surgery to either knee or bilateral ACL reconstruction; (2) underwent non-surgical management for their ACL injury;
(3) underwent a revision ACL reconstruction at the start of the study; (4) had a grade 3 PCL, MCL or LCL injury; (5) not written in English; and (6) studies were systematic reviews, narrative reviews, meta-analysis, editorials, letters to the editor or clinical commentaries. When two or more different studies used the same named cohort of participants, the study with the larger overall sample size was included in this review.

\section{Study selection}

Two reviewers (ADP, JML) independently screened all relevant titles and abstracts retrieved from the database search against the selection criteria. Full-text manuscripts of remaining eligible studies were evaluated with the same selection criteria. Any discrepancies between the two reviewers were resolved by a third reviewer (GSB). If further data clarification was necessary to establish study eligibility, contact with the corresponding and/ or senior listed author(s) was attempted via email with a 2-week follow-up email if no initial response.

\section{Assessment of risk of bias and strength of the evidence}

Two reviewers (ADP, JML) independently assessed risk of bias for each study. Any discrepancies were solved through discussion and consensus. A post hoc change was made to the study protocol to follow current systematic review best practice guidelines for assessing risk of bias using domain-based, study designspecific tools versus study methodological quality. ${ }^{45}$

We assessed risk of bias using three domain-based tools including the Cochrane Risk of Bias 2 tool for randomised controlled trials, the Risk of Bias Assessment tool for NonRandomized Studies for observational studies including cohort, case-control and before-after studies ${ }^{46}$ and the Cochrane Risk Of Bias In Non-randomized Studies - of Interventions tool for studies assessing the effect of interventions between groups. ${ }^{47}$ We assessed each tool for the primary outcome of second ACL injury only as this was most pertinent to this review. For the Risk of Bias 2 tool, risk of bias judgement per study is noted as 'low risk' when all domains are judged to be at 'low' risk of bias, 'some concerns' of bias when one or more domains are judged to be at 'some concerns', or 'high risk' of bias when at least one domain is judged to be at 'high' risk of bias or when multiple domains have 'some concerns' of bias. For the Risk of Bias Assessment tool for Non-Randomized Studies tool, risk of bias judgement per study is noted as 'high' risk if $\geq 2$ domains were rated as 'high' risk, $\geq 2$ 'unclear' risk, or 1 'unclear' and 1 'high' risk. For the Risk Of Bias In Non-randomized Studies of Interventions tool, risk of bias judgement per study is noted as 'low risk' when all domains are judged as 'low' risk of bias, 'moderate' risk when one domain is judged as 'moderate' risk of bias, 'serious' risk when one domain is judged as 'serious' risk of bias, or 'critical' risk of bias when one domain is judged as 'critical' risk of bias.

Strength of the evidence included in this review was judged using the Grading of Recommendations Assessment, Development and Evaluation (GRADE) scale, which determines the overall certainty of the evidence per outcome that is statistically pooled and compared between groups. ${ }^{48} 49$ The GRADE scale assesses five factors concerning risk of bias (see tool descriptions mentioned previously), imprecision (width of CIs) and publication bias (determined by funnel plot). These factors lead to a reported score of high, moderate, low or very low quality of the evidence. The GRADE scale was applied to assess the evidence regarding sex-based difference in total, ipsilateral and contralateral second ACL injury risk. The lead author (ADP) 


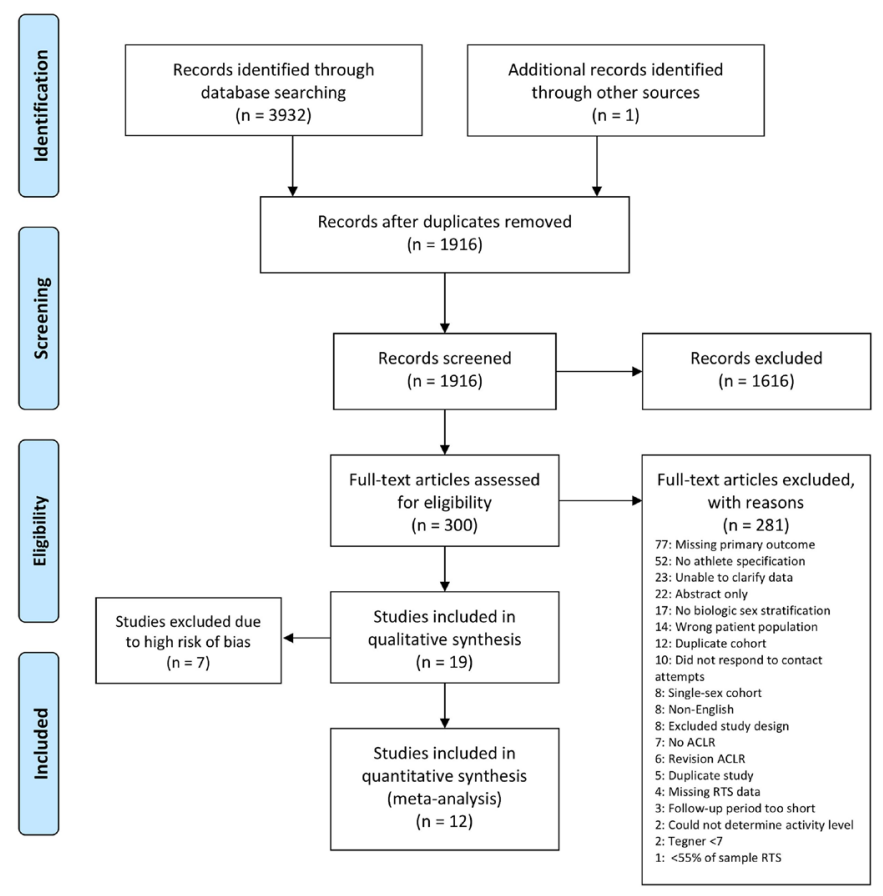

Figure 1 PRISMA flow diagram.

aggregated the necessary information for each GRADE domain and was reviewed by a second reviewer (JML) for accuracy and completeness. Any disagreements were settled through discussion and consensus.

\section{Data extraction and primary outcome variables}

Two reviewers (ADP, JML) independently extracted data from included studies using identical templates. Any discrepancies were solved through discussion and consensus. If further clarification on the reported data within included studies was necessary, contact with the listed corresponding authors was attempted. Study descriptive information including title, primary author, date of publication was recorded, as well as demographic information including sample size, participant age, participant sex, ACL reconstruction characteristics, pre-injury activity level, post-injury activity level, return-to-sport percentage and the diagnostic criteria used to determine a second ACL injury. To capture all possible second ACL injuries, diagnostic criteria used to determine a second ACL injury were not standardised in this review and determined via the methods used by each included study.

The primary outcome variables extracted were overall study incidence of a second ACL injury (graft rupture and native contralateral ACL injury), the incidence of a second ACL injury based on sex (male or female), incidence of second ACL injury based on which knee it occurred (contralateral or ipsilateral), and the incidence of a second ACL injury based on the interaction of sex and laterality of injury (contralateral or ipsilateral).
Statistical analyses

Per current meta-analyses best practice recommendations, ${ }^{450}$ all studies assessed to be at high risk of bias were excluded from the primary meta-analyses to reduce compounding of bias, ${ }^{450} 50$ but were included in our sensitivity analysis (described later). ${ }^{45}$ Aggregated random effects incidence proportions with 95\% CI were calculated for overall, ipsilateral and contralateral second ACL injuries for the total cohort and per sex. This calculation provides the cumulative incidence (expressed as a percentage) which is equivalent to the risk of experiencing a second ACL injury. ${ }^{51}$ Heterogeneity bias was assessed through BeggMazumdar and Egger's calculations, with $\mathrm{I}^{2}$ value reported (high heterogeneity: $I^{2} \geq 50 \%$, and $\mathrm{p}$ value $<0.10$ ).

To determine the relative and absolute risk of sustaining a second ACL injury between sexes, an inverse-weighted, DerSimonian and Laird random-effects risk ratio (RR) and risk difference meta-analysis were performed for overall, ipsilateral and contralateral second ACL injuries per sex at 95\% CI. Both relative (RR) and absolute (risk difference) were reported to give a clear picture of the clinical relevance of the pooled estimates. ${ }^{52}$ Pooled RR and risk difference statistics are reported with males as the reference population; thus, the calculations were $R R=(\mathrm{fe}-$ male cumulative incidence/male cumulative incidence), risk difference $=($ female cumulative incidence-male cumulative incidence). Heterogeneity bias was assessed through Cochrane's Q and $\mathrm{I}^{2}$, with high heterogeneity determined with an $\mathrm{I}^{2} \geq 50 \%$ and a $\mathrm{p}$ value $<0.10$. Publication bias was assessed through funnel plots. Meta-regressions were then performed to determine the influence of age, pre-injury activity level and study return-tosport percentage on overall, ipsilateral and contralateral second ACL injuries per sex. The variance explained through these confounders was assessed through $\mathrm{R}^{2}$.

Sensitivity analyses were then performed to further understand the robustness of our results and the directions of biases. To determine if return-to-sport percentage introduced bias into our study, sensitivity analyses included studies that reported $\geq 85 \%$ return-to-sport. Further, to understand the direction and effect of bias in this literature, we performed a sensitivity analysis that included all studies, regardless of bias assessment (high risk of bias studies $(n=7)$ included). Incidence proportion analyses were performed in StatsDirect (StatsDirect, Merceyside, UK) and all $\mathrm{RR}$ and risk difference meta-analyses and meta-regressions were performed in R V.5.042 (R Core Team (2013). R: A language and environment for statistical computing. $\mathrm{R}$ Foundation for Statistical Computing, Vienna, Austria. URL http://www.Rproject.org/) using the meta package.

\section{RESULTS}

\section{Search results}

The initial search resulted in 3932 potentially eligible studies, with one additional article discovered during the manual search that met our inclusion criteria (figure 1). After removal of duplicates, 1916 studies remained. Screening of title and abstracts yielded 300 studies for full-text analysis. Overall, 281 full-text articles were excluded for a variety of reasons as indicated in

Table 1A Risk of bias assessment: randomised controlled trials (Cochrane Risk of Bias 2 Tool)

\begin{tabular}{lllllllll}
\hline Study & $\begin{array}{l}\text { Sequence } \\
\text { generation }\end{array}$ & $\begin{array}{l}\text { Allocation } \\
\text { concealment }\end{array}$ & $\begin{array}{l}\text { Blinding of } \\
\text { participants }\end{array}$ & $\begin{array}{l}\text { Blinding of outcome } \\
\text { assessors }\end{array}$ & Incomplete data & $\begin{array}{l}\text { Selective outcome } \\
\text { reporting }\end{array}$ & $\begin{array}{l}\text { Other } \\
\text { sources }\end{array}$ & Overall \\
\hline Fleming et $a l^{55}$ & High & Low & Low & Some concerns & Some concerns & Low & Low & High \\
Mohtadi $e t a l^{68}$ & Low & Low & Low & Low & Low & Low & Low & Low \\
\hline
\end{tabular}




\begin{tabular}{|c|c|c|c|c|c|c|c|}
\hline Study & Confounding & $\begin{array}{l}\text { Participant } \\
\text { selection }\end{array}$ & $\begin{array}{l}\text { Blinding of outcome } \\
\text { assessors }\end{array}$ & Missing data & $\begin{array}{l}\text { Exposure } \\
\text { measurement }\end{array}$ & $\begin{array}{l}\text { Selective outcome } \\
\text { reporting }\end{array}$ & Overall \\
\hline Bak et al ${ }^{60}$ & Low & Low & Low & Low & Low & Low & Low \\
\hline Beischer et $a^{61}$ & Low & Low & Low & High & Low & Low & Low \\
\hline Bourke et $a^{62}$ & Low & Low & Low & Low & Low & Low & Low \\
\hline Cordasco et $a^{53}$ & Low & High & Unclear & Low & Low & Low & High \\
\hline Dekker et al/ ${ }^{63}$ & Low & Low & Low & High & Low & Low & Low \\
\hline Demange et $\left.a\right|^{54}$ & Low & High & Unclear & Low & High & Low & High \\
\hline Geffroy et a $\left.\right|^{56}$ & Low & Low & Unclear & Low & High & Low & High \\
\hline Graziano et $a^{57}$ & Low & High & Low & Low & Unclear & Low & High \\
\hline Gupta et $a l^{58}$ & Low & Low & Unclear & Low & Low & High & High \\
\hline Heath et $a l^{65}$ & Low & Low & Low & Low & Low & Low & Low \\
\hline Kamath et $a^{67}$ & Low & Low & Low & Low & Low & Low & Low \\
\hline Laboute et $a^{59}$ & High & Low & Unclear & High & High & High & High \\
\hline Paterno et a $\beta^{30}$ & Low & Low & Low & Low & High & Low & Low \\
\hline Shelbourne et $a \beta^{38}$ & Low & Low & Low & Low & Low & Low & Low \\
\hline Webster et $a^{69}$ & Low & Low & Low & Low & Low & Low & Low \\
\hline
\end{tabular}

figure 1 . We contacted the corresponding authors of 49 studies via email and requested clarifying data (online supplemental appendix 2). Of these, 6 studies (12.2\%) provided clarifying data that was used in this review (online supplemental appendix 2). The remaining 43 studies either provided clarifying data that excluded the study, did not provide clarifying data or the corresponding author did not respond (online supplemental appendix 2). Thus, 19 studies met the inclusion criteria for our qualitative synthesis (figure 1 ).

\section{Risk of bias, GRADE and AMSTAR-2}

Seven studies $(36.8 \%)$ were found to be at high risk of bias. ${ }^{53-59}$ The remaining 12 were determined to be at low $(n=11,57.9 \%)$ or moderate $(n=1,5.3 \%)$ risk of bias ${ }^{303860-69}$ (tables 1A-C).

The GRADE scale determined that the quality of evidence for the risk of sustaining a second ACL injury and ipsilateral ACL injury is 'very low quality', due to imprecision of the pooled RR and risk difference estimates and high levels of heterogeneity (online supplemental appendix 3). The quality of evidence for the risk of a contralateral ACL injury is 'low quality' because non-randomised studies were included (online supplemental appendix 3). This review met 15 of 16 reporting and quality items (94\%) according to the AMSTAR-2 criteria (online supplemental appendix 4).

\section{Study characteristics and demographics}

Study demographic information, sample size, ACL reconstruction characteristics, activity levels, return-to-sport percentage and definition of a second ACL injury from all 19 included studies are available in table 2. From the 19 included studies, there were 4027 total participants (females=1715 (42.6\%), males $=2312(57.4 \%))^{30} 3853-69$ (online supplemental appendix $5)$. Seven studies were excluded from our primary analysis due to high risk of bias. ${ }^{53-59}$ Thus, 12 studies with 2944 participants
$($ females $=1431(48.6 \%)$, males $=1513(51.4 \%))$ were included in the primary meta-analyses. ${ }^{30} 3860-69$

\section{Second ACL injury risk}

Primary meta-analysis estimated the pooled risk of a second ACL injury for the total cohort and by sex, which are presented in figure $2 \mathrm{~A}-\mathrm{C}$. The pooled risk of a second ACL injury (either graft tear or contralateral ACL injury) for both males and females was 21.9\% (95\% CI $16.7 \%$ to $27.6 \%, \mathrm{I}^{2}=92 \%$ ). ${ }^{30} 3860-69$ Females were found to be at $22.8 \%$ (95\% CI $16.6 \%$ to $29.6 \%, \mathrm{I}^{2}=88 \%$ ) risk for a second ACL injury. Males were found to be at $20.3 \%$ (95\% CI $13.6 \%$ to $27.8 \%, \mathrm{I}^{2}=91 \%$ ) risk for a second ACL injury.

Pooled risk of an ipsilateral ACL injury (for the total cohort and by sex) and contralateral ACL injury (for the total cohort and by sex) are presented in figure $3 \mathrm{~A}-\mathrm{C}$ (ipsilateral) and figure $4 \mathrm{~A}-\mathrm{C}$ (contralateral).

Of all male second ACL injuries, ipsilateral injuries accounted for $62.5 \%$ (95\% CI $52.4 \%$ to $72.1 \%, \mathrm{I}^{2}=64 \%$ ) of those injuries, with contralateral injuries accounting for $37.5 \%(95 \% \mathrm{CI}$ $27.9 \%$ to $47.6 \%, \mathrm{I}^{2}=64 \%$ ) of all male injuries (figure $5 \mathrm{~A}, \mathrm{~B}$ ). Of all female second ACL injuries, contralateral injuries account for $53.7 \%$ (95\% CI $41.9 \%$ to $65.4 \%, \mathrm{I}^{2}=74 \%$ ) of those injuries, while ipsilateral injuries accounted for $46.3 \%$ (95\% CI $34.6 \%$ to $58.1 \%, \mathrm{I}^{2}=74 \%$ ) of all female injuries (figure $6 \mathrm{~A}, \mathrm{~B}$ ).

\section{Relative and absolute differences in second ACL risk by sex}

Primary meta-analysis revealed there were no statistically significant differences between sexes in the relative risk of second ACL injury $\left(\mathrm{RR}=0.95,95 \% \mathrm{CI} 0.75\right.$ to $\left.1.19, \mathrm{p}=0.629, \mathrm{I}^{2}=50 \%\right)$ (figure $7 \mathrm{~A}$ ) or in the absolute risk of second ACL injury (risk difference $=-0.6 \%, 95 \% \mathrm{CI}-4.9$ to $\left.3.7, \mathrm{p}=0.783, \mathrm{I}^{2}=41 \%\right)$. There was no statistically significant difference between sexes in ipsilateral ACL injury relative risk $(\mathrm{RR}=0.74,95 \% \mathrm{CI} 0.52$ to $1.05, \mathrm{p}=0.094, \mathrm{I}^{2}=52 \%$ ) (figure $7 \mathrm{~B}$ ). However, females were

\begin{tabular}{|c|c|c|c|c|c|c|c|c|}
\hline Study & Confounding & $\begin{array}{l}\text { Participant } \\
\text { selection }\end{array}$ & $\begin{array}{l}\text { Classification of } \\
\text { interventions }\end{array}$ & $\begin{array}{l}\text { Deviation from intended } \\
\text { intervention }\end{array}$ & $\begin{array}{l}\text { Missing } \\
\text { data }\end{array}$ & $\begin{array}{l}\text { Outcome } \\
\text { measurement }\end{array}$ & $\begin{array}{l}\text { Selective outcome } \\
\text { reporting }\end{array}$ & Overall \\
\hline Everhart et a $\left.\right|^{64}$ & Low & Low & Low & Low & Low & Moderate & Low & Moderate \\
\hline Heijne et $a^{166}$ & Low & Low & Low & Low & Low & Low & Low & Low \\
\hline
\end{tabular}




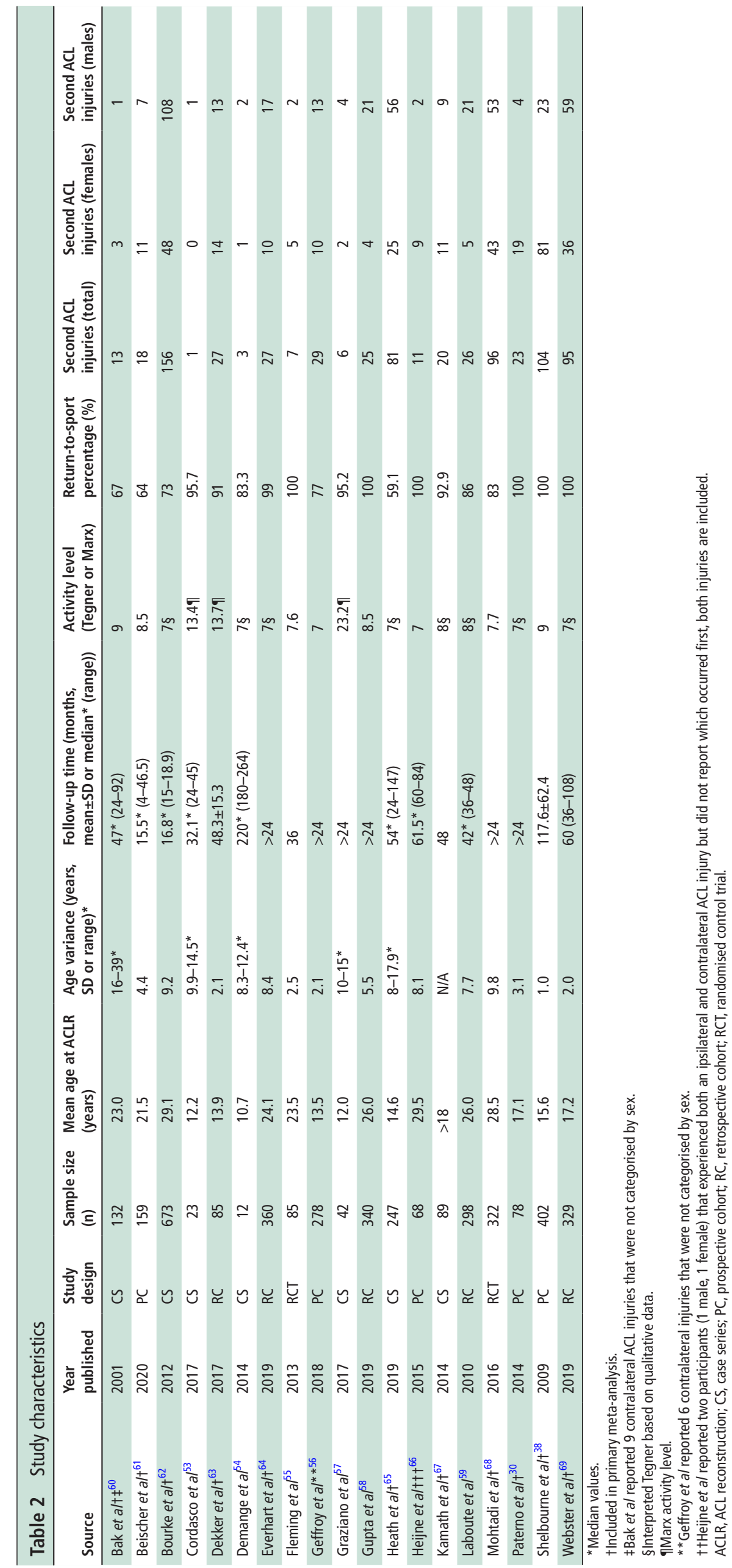

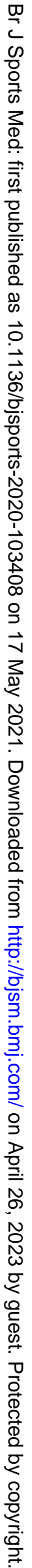



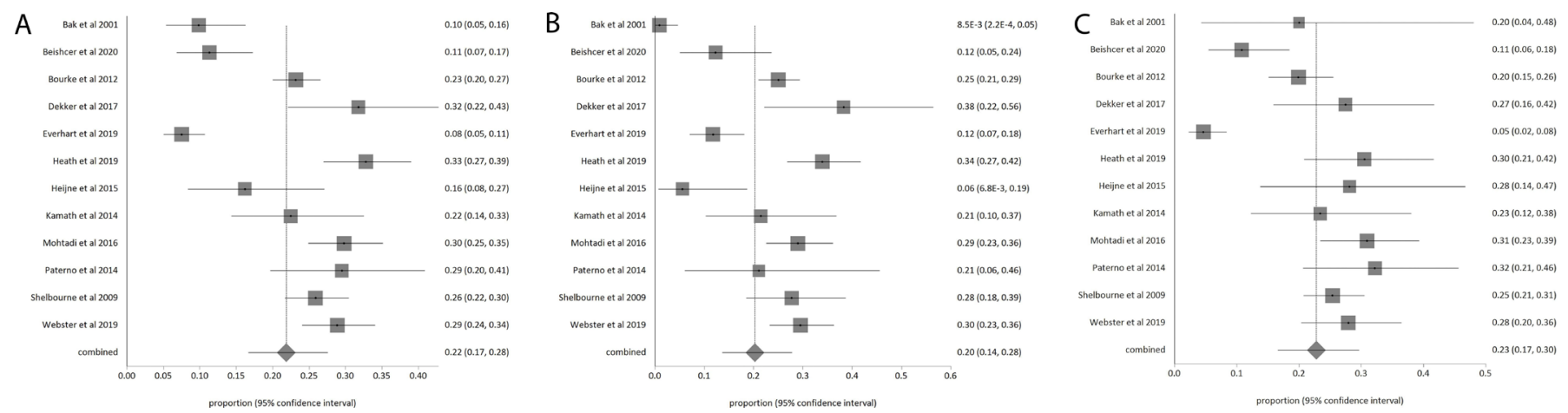

Figure 2 (A) Total cohort second ACL injury risk. Forest plot for the incidence proportion (risk) and $95 \% \mathrm{Cl}$ of experiencing a second $\mathrm{ACL}$ injury (ipsilateral and contralateral) in both male and female athletes combined. (B) Male second ACL injury risk forest plot for the incidence proportion (risk) and $95 \% \mathrm{Cl}$ of experiencing a second $\mathrm{ACL}$ injury (ipsilateral and contralateral) in male athletes. (C) Female second $\mathrm{ACL}$ injury risk forest plot for the incidence proportion (risk) and $95 \% \mathrm{Cl}$ of experiencing a second $\mathrm{ACL}$ injury (ipsilateral and contralateral) in female athletes.

found to have $3.4 \%$ reduced absolute risk of an ipsilateral ACL injury compared with males (risk difference $=-3.4 \%, 95 \% \mathrm{CI}$ $-6.7 \%$ to $\left.-0.02 \%, \mathrm{p}=0.037, \mathrm{I}^{2}=35 \%\right)$. Females were found to have 1.27 times higher relative risk $(95 \%$ CI 1.00 to 1.61 , $\left.\mathrm{p}=0.049, \mathrm{I}^{2}=0 \%\right)$ of experiencing a contralateral ACL injury compared with males (figure $7 \mathrm{C}$ ). Females were found to have a non-statistically significant, $1.9 \%$ increase in the absolute risk of experiencing a contralateral ACL injury compared with males ( $95 \% \mathrm{CI}-0.5 \%$ to $\left.4.4 \%, \mathrm{p}=0.113, \mathrm{I}^{2}=15 \%\right)$.

Funnel plot assessment did not indicate concern for publication bias (online supplemental appendix 6). Meta-regression performed using participant age, pre-injury activity level and study return-to-sport percentage as moderators of second ACL injury, ipsilateral ACL injury and contralateral ACL injury risk revealed these factors did not impact the pooled risk values $\left(\mathrm{R}^{2}=0.0 \%\right.$ for all three analyses).

\section{Sensitivity analysis}

Sensitivity analysis performed including studies with a sample return-to-sport percentage $\geq 85 \%(n=6)$ showed no statistically significant differences in the relative risk of sustaining a second ACL injury between sexes ( $\mathrm{RR}=0.86,95 \% \mathrm{CI} 0.66$ to $1.12, \mathrm{p}=0.273)$ or a native contralateral $\mathrm{ACL}$ injury $(\mathrm{RR}=1.26$, $95 \%$ CI 0.83 to $1.90, p=0.281)$. However, females were found to be at a $41 \%$ reduced relative risk $(\mathrm{RR}=0.59,95 \% \mathrm{CI} 0.42$ to
$0.85, \mathrm{p}=0.004)$ of an ipsilateral injury compared with males in studies with high return-to-sport percentage $(\geq 85 \%)$.

High risk of bias studies were added back into the primary meta-analysis $(n=7)^{53-59}$ to determine the effect and direction of observed bias in the available literature. This sensitivity analysis found no statistically significant difference between sexes in the overall relative risk of sustaining a second ACL injury $\left(\mathrm{RR}=0.98,95 \% \mathrm{CI} 0.81\right.$ to $\left.1.18, \mathrm{p}=0.799, \mathrm{I}^{2}=32 \%\right)$. However, females were found to be at $29 \%$ reduced relative risk of an ipsilateral ACL injury ( $R R=0.71,95 \% \mathrm{CI} 0.58$ to $0.87, \mathrm{p}=0.0008$, $\left.\mathrm{I}^{2}=0 \%\right)$ compared with males, and females were found to have 1.35 times greater relative risk of experiencing a native contralateral ACL injury compared with males $(\mathrm{RR}=1.35,95 \% \mathrm{CI}$ 1.07 to $\left.1.70, \mathrm{p}=0.011, \mathrm{I}^{2}=0 \%\right)$.

\section{DISCUSSION}

Currently, there is ambiguity regarding the relationship between sex and second ACL injury risk following primary ACL reconstruction. The results of this systematic review and primary metaanalysis determined that there is a negligible, non-statistically significant difference in the relative and absolute risk of experiencing a second ACL injury (both ipsilateral and contralateral combined) between sexes. Females may experience a small, 3.4\% reduced absolute risk of a subsequent ipsilateral ACL injury compared with males. This review also found that females may
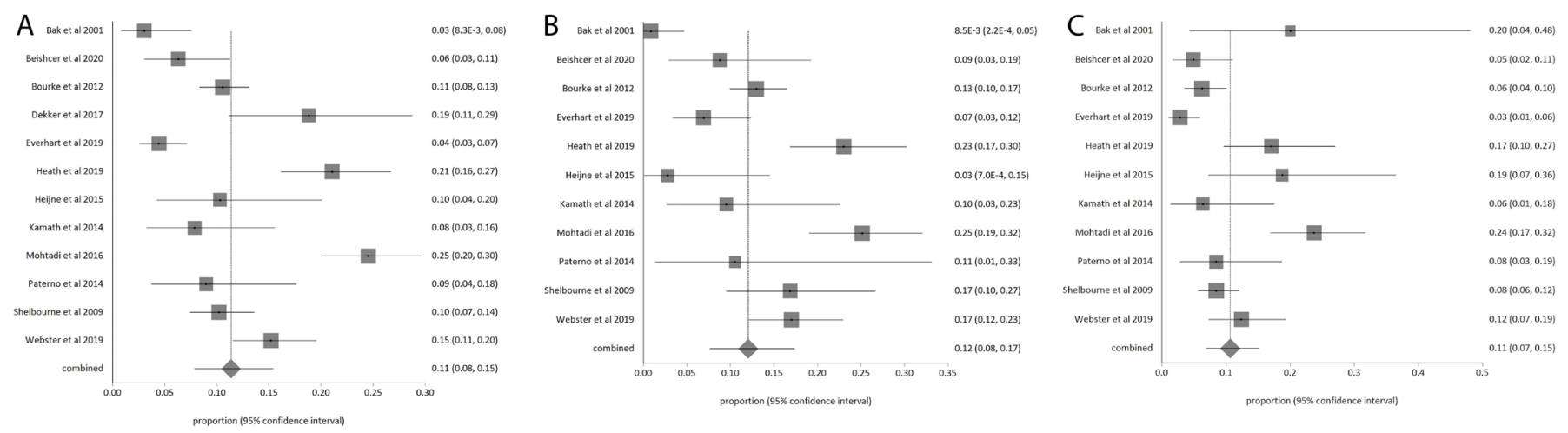

Figure 3 (A) Total cohort ipsilateral second $\mathrm{ACL}$ injury risk. Forest plot for the incidence proportion (risk) and $95 \% \mathrm{Cl}$ of experiencing an ipsilateral $\mathrm{ACL}$ injury in both male and female athletes combined. (B) Male ipsilateral second ACL injury risk. Forest plot for the incidence proportion (risk) and $95 \% \mathrm{Cl}$ of experiencing an ipsilateral $\mathrm{ACL}$ injury in male athletes. Dekker et $a l^{63}$ was excluded from this analysis because data were not provided to quantify the number of male ipsilateral injuries. (C) Female ipsilateral second $\mathrm{ACL}$ injury risk. Forest plot for the incidence proportion (risk) and $95 \% \mathrm{Cl}$ of experiencing an ipsilateral $\mathrm{ACL}$ injury in female athletes. Dekker et $\mathrm{al}^{63}$ was excluded from this analysis because data were not provided to quantify the number of female ipsilateral injuries. 

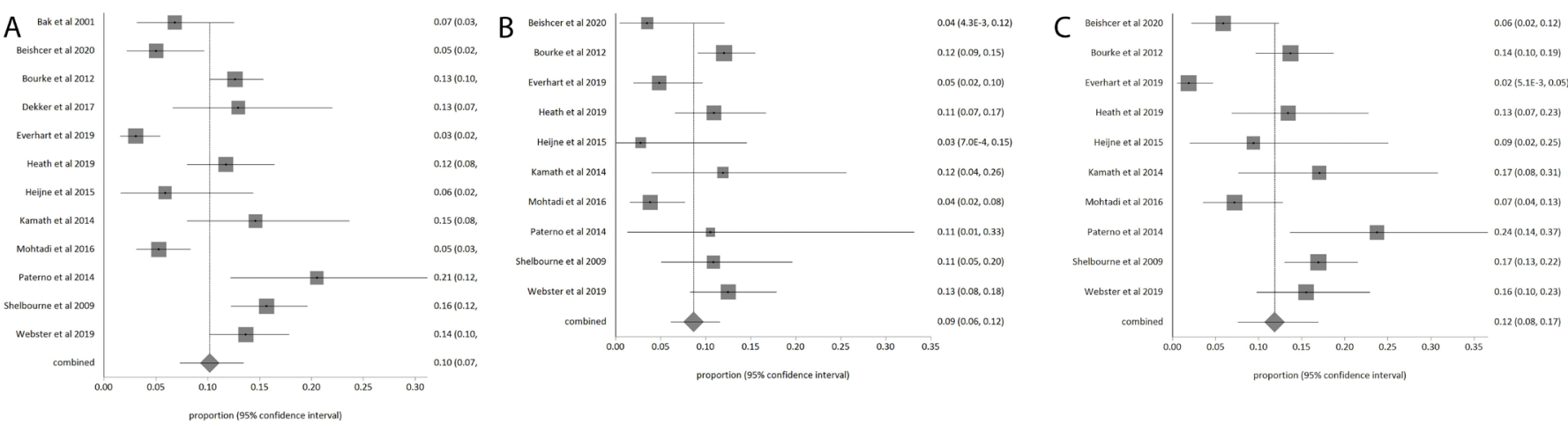

Figure 4 (A) Total cohort contralateral second $\mathrm{ACL}$ injury risk. Forest plot for the incidence proportion (risk) and $95 \% \mathrm{Cl}$ of experiencing an contralateral $\mathrm{ACL}$ injury in both male and female athletes combined. (B) Male contralateral second $\mathrm{ACL}$ injury risk. Forest plot for the incidence proportion (risk) and $95 \% \mathrm{Cl}$ of experiencing an ipsilateral $\mathrm{ACL}$ injury in male athletes. Bak et a ${ }^{60}$ and Dekker et a ${ }^{63}$ were excluded from this analysis because data were not provided to quantify the number of male contralateral injuries. (C) Female contralateral second ACL injury risk. Forest plot for the incidence proportion (risk) and $95 \% \mathrm{Cl}$ of experiencing an ipsilateral $\mathrm{ACL}$ injury in female athletes. Bak et al ${ }^{60}$ and Dekker et al ${ }^{63}$ were excluded from this analysis because data were not provided to quantify the number of female contralateral injuries.

experience 1.27 times higher relative risk of a subsequent contralateral ACL injury compared with males $(95 \%$ CI 1.00 to 1.61 , $\mathrm{p}=0.049$ ). However, females were found to have only a small, non-statistically significant, absolute increase in subsequent contralateral ACL injury risk compared with males (risk difference $=1.9 \%, 95 \% \mathrm{CI}-0.5 \%$ to $4.4 \%, \mathrm{p}=0.113$ ). This suggests that any difference in subsequent contralateral ACL injury risk between sexes is minimal at best.

\section{Risk of a second ACL injury}

Males and females were found to be equally likely to experience a second ACL injury. Although a previous meta-analysis reported that females have higher odds of experiencing a second ACL injury than males, ${ }^{70}$ this discrepancy is likely due to the absence of considering return-to-sport percentage in their inclusion criteria. This suggests that their findings might better reflect general populace ACL injury trends. Having considered returnto-sport percentage, the present review reflects active individuals attempting to return to their prior level of activity and exposing themselves to higher levels of ACL re-injury risk.

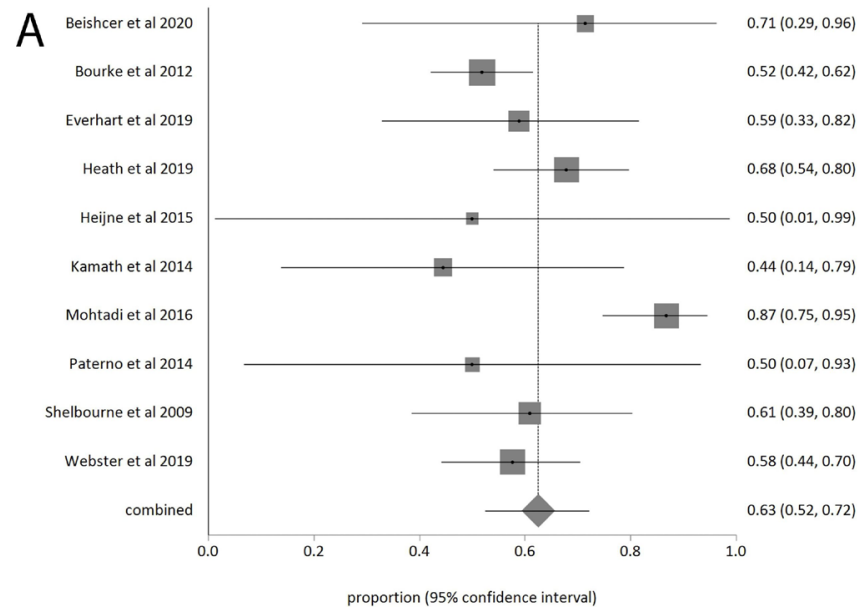

Although females have been considered to be at increased risk of a contralateral ACL injury compared with an ipsilateral ACL injury, ${ }^{30}$ we found that females experience similar risk of sustaining an ipsilateral (11\%) and contralateral (12\%) ACL injury (figures 3C and 4C). However, differences between ipsilateral and contralateral ACL injury trends may occur at different rates. ${ }^{4}$ When factoring in time from return-to-sport to injury, females demonstrate a considerably increased rate of a contralateral ACL injury compared with an ipsilateral ACL injury. ${ }^{30}$ Our review did not factor in the rate of second ACL injuries because our focus was on determining the risk of second ACL injuries between sexes.

The primary analysis found that females demonstrated a small, $3.5 \%$ reduced absolute risk of experiencing an ipsilateral ACL injury compared with males. However, due to the number of statistical tests performed, this could be the result of type 1 error. Further, additive and multiplicative risks are not completely equal in analysis, ${ }^{71}$ with additive risk potentially providing improved multivariable risk assessment for multiple exposures, time to event hazards, and overall public health impact. ${ }^{71} 72$

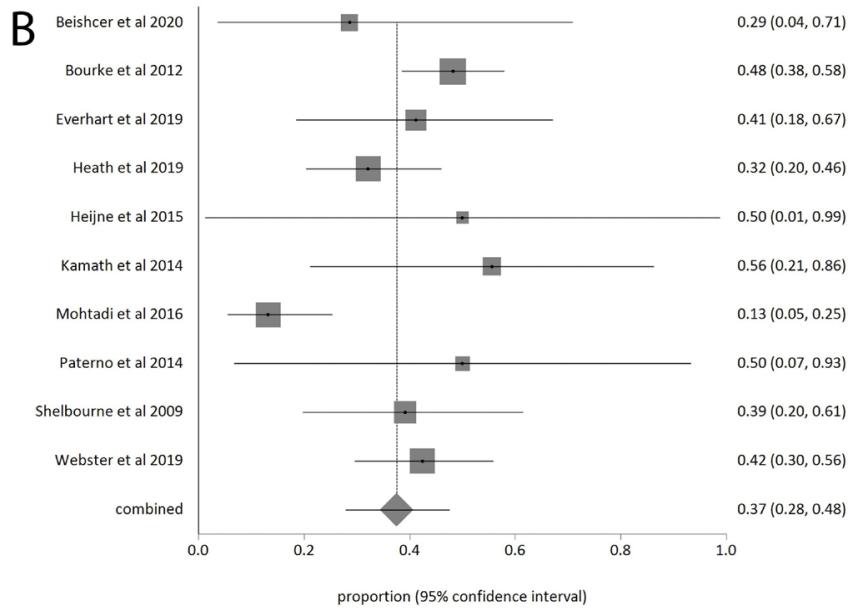

Figure 5 (A) Proportion of male second ACL injuries to the ipsilateral $\mathrm{ACL}$. Forest plot for the proportion and $95 \% \mathrm{Cl}$ of ipsilateral $\mathrm{ACL}$ injuries experienced in male athletes. Bak et $a^{60}$ and Dekker et $\mathrm{a}^{63}$ were excluded from this analysis because data were not provided to quantify the number of both ipsilateral and contralateral injuries in males. (B) Proportion of male second ACL injuries to the contralateral ACL. Forest plot for the proportion and $95 \% \mathrm{Cl}$ of contralateral $\mathrm{ACL}$ injuries experienced in male athletes. Bak et $\mathrm{a} /{ }^{60}$ and Dekker et $a l^{63}$ were excluded from this analysis because data were not provided to quantify the number of both ipsilateral and contralateral injuries in males. 

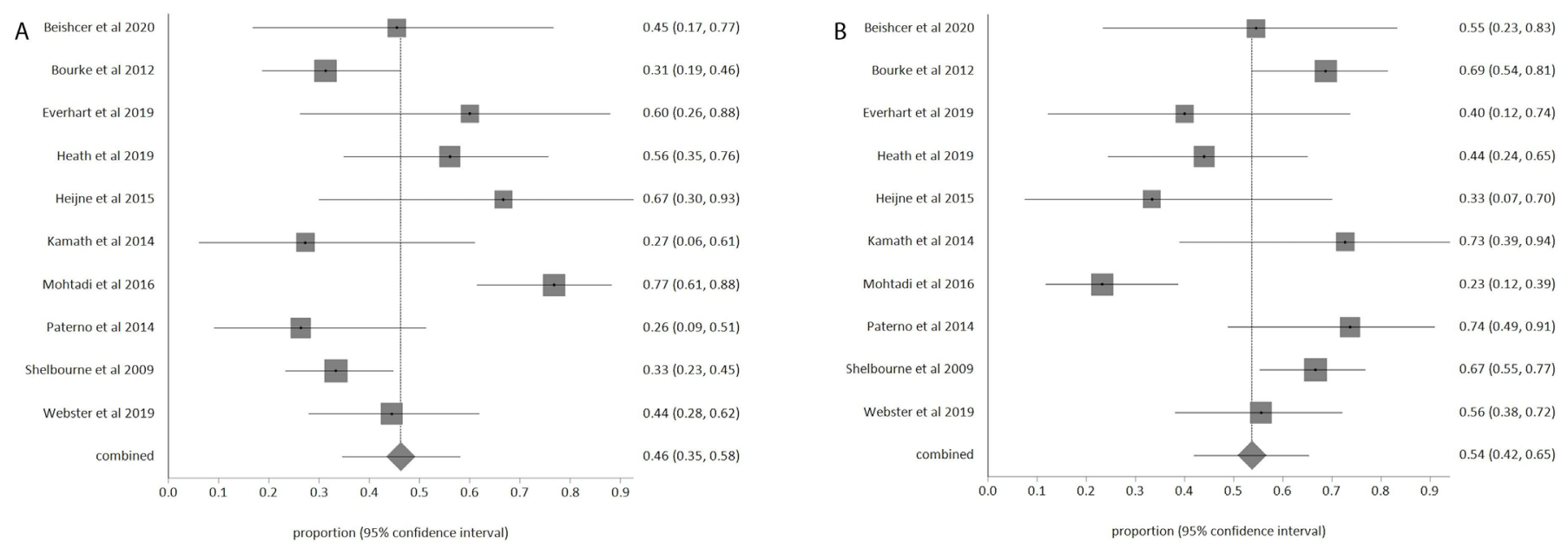

Figure 6 (A) Proportion of female second ACL injuries to the ipsilateral ACL. Forest plot for the proportion and $95 \% \mathrm{Cl}$ of ipsilateral $\mathrm{ACL}$ injuries experienced in female athletes. Bak et $a l^{60}$ and Dekker et $a l^{63}$ were excluded from this analysis because data were not provided to quantify the number of both ipsilateral and contralateral injuries in females. (B) Proportion of female second ACL injuries to the contralateral ACL. Forest plot for the proportion and $95 \% \mathrm{Cl}$ of contralateral $\mathrm{ACL}$ injuries experienced in female athletes. Bak et $a^{/ 60}$ and Dekker et $a /^{63}$ were excluded from this analysis because data were not provided to quantify the number of both ipsilateral and contralateral injuries in females.

While this review estimates there may be only negligible to small (and some not statistically significant) pooled sex-based differences in second ACL injury risk by injury laterality (ipsilateral vs contralateral), it is critical to note that both groups are still at $>20 \%$ risk for either an ipsilateral or contralateral second ACL injury. Since both limbs remain at risk for a future ACL injury, this provides further evidence that suggests the contralateral limb may not be the most useful comparator when making rehabilitation and return to sport decisions. ${ }^{3673-76}$ There needs to be continued efforts towards optimising rehabilitation, ${ }^{77}$ and standardising return-to-sport criteria and comparison metrics that limit reliance on the also at-risk contralateral limb. ${ }^{73}$

The primary analysis also found that males appear to experience a larger proportion of ipsilateral second ACL injuries (62.5\%) compared with contralateral ACL injuries (37.5\%). These findings may be explained by the already present differences in baseline primary ACL injury risk between sexes (one in 29 females sustains a primary ACL injury compared with one in 50 males). ${ }^{4}$ One theoretical explanation for this second ACL injury trend is that both sexes may retain their baseline primary ACL injury risk following ACL reconstruction such that both limbs remain at elevated risk for an ACL injury in females, while males might have increased risk factors in the reconstructed (ie, ipsilateral) ACL, increasing injury risk compared with the uninjured (ie, contralateral) ACL. Because males are at much lower baseline risk of injury compared with females, ${ }^{4}$ surgical reconstruction and subsequent reduction in strength and function (ie, knee joint loading, movement patterns, psychological aspects of recovery) of that limb may be the strongest factors affecting ipsilateral graft injuries in males. ${ }^{78} 79$ This trend and its explanation require further research to understand the mechanism that underlies the higher proportion of male ipsilateral ACL injuries versus contralateral ACL injuries.

Age did not explain any variance within these findings. This may be due to the strict inclusion criteria used in the current study. The included studies demonstrated a homogenous age range and did not capture a substantial proportion of younger individuals ( $<18$ years). Only 4 of the 12 studies in the primary meta-analysis had populations $<18$ years old, while 5 of the 7 studies excluded due to high risk of bias had populations $<18$ years old. Females have been shown in population-based studies to have a peak incidence of ACL injuries ${ }^{80} 81$ and higher risk of a second ACL injury when they are $<19$ years old. ${ }^{29} 3036$ Males appear to experience peak incidence of primary ACL injury in their mid-20s. ${ }^{80} 81 \mathrm{~A}$ recent meta-analysis assessing second ACL injury differences between sexes following paediatric ACL reconstruction found that females experienced more contralateral injuries compared with males, but they did not calculate a meaningful measure of association that informs the magnitude and direction of the relationship. ${ }^{82}$ Further methodological concerns include inappropriate statistical pooling and comparisons which indicate these results should be interpreted with caution. Recent evidence has challenged the notion of age as a risk factor for second ACL injury and concluded that functional readiness and returning to level 1 sport are the key factors associated with second ACL injury risk, ${ }^{83}$ leading to continued ambiguity regarding the interaction between age and sex on second ACL injury risk.

\section{Risk of bias}

This review identified seven studies $(36.8 \%)$ considered to be at high risk of bias and were removed from our primary analyses to not compound bias.(tables $1 \mathrm{~A}-\mathrm{C}$ ) To assess the effect of high risk of bias studies on pooled second ACL injury estimates, a sensitivity analysis was performed which included the high risk of bias studies. These results suggest that including high risk of bias studies can exaggerate relative risk estimates away from the null; with the risk of females experiencing an ipsilateral ACL injury decreasing from $\mathrm{RR}=0.74$ (95\% CI 0.52 to 1.05$)$ to $\mathrm{RR}=0.71$ (95\% CI 0.58 to 0.87 ). Similarly, female contralateral ACL injury risk increased from $\mathrm{RR}=1.27$ (95\% CI 1.00 to 1.60$)$ to $\mathrm{RR}=1.34$ (95\% CI 1.07 to 1.70 ). The risk of bias concerns and noted high heterogeneity $\left(\mathrm{I}^{2}>50 \%\right)$ seen in most analyses dictate that studies examining second ACL injury outcomes should ensure they adhere to established guidelines (eg, STROBE or CONSORT) in the design and execution of the final manuscript to ensure potential sources of bias are mitigated. ${ }^{84-86}$ Of note, the Panther Symposium and Consensus Statements have been recently published and should provide an in-depth guide to 

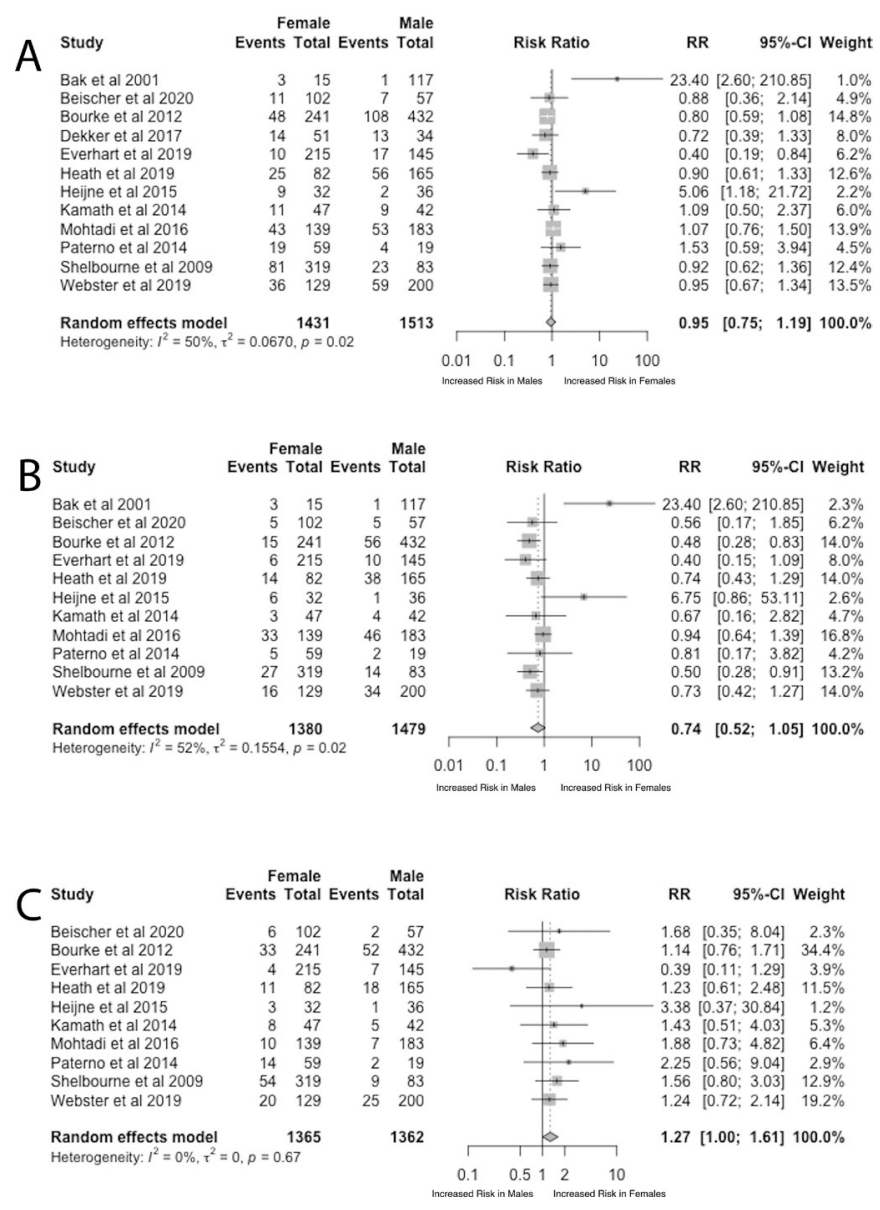

Figure 7 (A) Relative risk of a second ACL injury. Forest plot of the relative risk and $95 \% \mathrm{Cl}$ of experiencing a second $\mathrm{ACL}$ injury between sexes. Males are the reference population. Riski ratio (RR) $>1$ : increased risk in females, $R R<1$ : increased risk in males. (B) Relative risk of an ipsilateral $\mathrm{ACL}$ injury. Forest plot of the relative risk and $95 \% \mathrm{Cl}$ of experiencing an ipsilateral $A C L$ injury between sexes. Males are the reference population. $R R>1$ : increased risk in females, $R R<1$ : increased risk in males. Dekker et $a{ }^{63}$ was excluded from this analysis because data were not provided to quantify the number of female or male ipsilateral injuries. (C) Relative risk of a contralateral $\mathrm{ACL}$ injury. Forest plot of the relative risk and $95 \% \mathrm{Cl}$ of experiencing a contralateral $A C L$ injury between sexes. Males are the reference population. RR $>1$ : increased risk in females, $\mathrm{RR}<1$ : increased risk in males. Bak et $\mathrm{a} /{ }^{60}$ and Dekker et $a^{63}$ were excluded from this analysis because data were not provided to quantify the number of female or male contralateral injuries.

help standardise the research on ACL reconstruction outcomes, including return-to-sport outcomes and second ACL injury definitions. ${ }^{85}$

\section{Limitations}

We removed 36 potentially eligible studies because data were unable to be clarified, thus the pooled estimates and conclusions from this study could have been different due to a selection bias. We acknowledge that all researchers/clinicians involved in those studies were experiencing unforeseen challenges due to the COVID-19 pandemic that could have decreased our response rate and their ability to facilitate our requests. We did not factor in return-to-sport testing or psychological readiness within this analysis. It is plausible there could have been a significant difference in the risk of a second ACL injury had participants received
What is already known

- Female athletes are at increased risk for sustaining a primary $\mathrm{ACL}$ injury compared with males when playing the same sport.

What are the new findings?

- Both sexes are at $>20 \%$ risk of experiencing a second $\mathrm{ACL}$ injury.

- There is a negligible difference in the absolute risk of experiencing a second $\mathrm{ACL}$ injury between sexes (risk difference $=-0.6 \%, 95 \% \mathrm{Cl}-4.9$ to 3.7 ).

- Females may have a small reduction in the absolute risk of an ipsilateral second ACL injury compared with males (risk difference $=-3.4 \%, 95 \% \mathrm{Cl}-6.7 \%$ to $-0.02 \%)$.

objective clearance based on commonly recommended assessments. We did not standardise the diagnostic criteria of a second ACL injury, which could explain the considerable heterogeneity seen in our per-sex risk estimates. However, we sought to capture all studies with potentially valuable data; and our approach factors in all possible diagnostic and treatment schemes one may experience following a second ACL injury (surgical revision, imaging, clinical examination without imaging, non-operative care and/or KT-1000 arthrometer testing). We only established a minimum follow-up period of 12 months following ACL reconstruction to ensure we captured the early phases of return-tosport attempts and did not set a follow-up duration limit. We acknowledge there could potentially be studies with second ACL injury data but less than 12 months of follow-up that could have been missed in this review, leading to an underestimation of our estimates. Further, there may be a temporal factor (due to prolonged follow-up) that skewed our results due to continued (or reduced) exposure to risk, but previous literature refutes that association in primary ACL reconstruction. ${ }^{4}$ We also recognise that mechanism of injury likely impacts the risk of injury and for some of the proposed mechanisms for sex-based differences. However, few studies reported this information, limiting our ability to factor this into our analysis.

\section{CONCLUSION}

Both sexes are at $>20 \%$ increased risk of experiencing a second ACL injury. Overall, the magnitude of differences in the absolute risk of a subsequent ipsilateral or contralateral ACL injury between sexes appears small and potentially not clinically meaningful. Studies noting high return to sport percentages $(>85 \%)$ demonstrate that males may be at increased risk of experiencing a subsequent ipsilateral ACL injury compared with females.

Twitter Garrett S Bullock @DRGSBullock and Justin M Losciale @JayLos18

Acknowledgements We would like to thank Leila Ledbetter, MLIS for providing her guidance and assistance with generating the search and providing resources to optimise data management.

Contributors AP was first author on this paper; he conducted the screening for articles, conducted the data gathering, wrote the paper and edited the paper. GSB conducted statistical analysis of the paper, helped to write the paper, edited the paper and provided expertise on the subject matter. JW conducted the search for articles for the paper. MP edited the paper and provided expertise on the subject matter. TS initiated the paper topic, edited the paper and provided expertise on the subject matter. JL was principal investigator on this paper; he conducted the screening for articles, conducted the data gathering, helped write the paper, edited 
the paper and provided expertise on the subject matter. In addition, Leila Ledbetter, a contributor, provided guidance and assistance with generating the search and providing resources to optimise data management. All authors contributed to the writing, interpretation, critical revision and approval of the manuscript. AP, GSB, TS and JL conceived the research question. JW developed and executed the systematic literature search with input from JL, TS and GSB. AP, JL and GSB performed data extraction. GSB and JL performed statistical analysis and figure generation with input from TS and MP.

Funding The authors have not declared a specific grant for this research from any funding agency in the public, commercial or not-for-profit sectors.

Competing interests None declared.

Patient consent for publication Not required.

Provenance and peer review Not commissioned; externally peer reviewed.

Supplemental material This content has been supplied by the author(s). It has not been vetted by BMJ Publishing Group Limited (BMJ) and may not have been peer-reviewed. Any opinions or recommendations discussed are solely those of the author(s) and are not endorsed by BMJ. BMJ disclaims all liability and responsibility arising from any reliance placed on the content. Where the content includes any translated material, BMJ does not warrant the accuracy and reliability of the translations (including but not limited to local regulations, clinical guidelines, terminology, drug names and drug dosages), and is not responsible for any error and/or omissions arising from translation and adaptation or otherwise.

\section{ORCID iDs}

Akash D Patel http://orcid.org/0000-0001-9397-9630

Garrett S Bullock http://orcid.org/0000-0003-0236-9015

Justin M Losciale http://orcid.org/0000-0001-5135-1191

\section{REFERENCES}

1 Agel J, Rockwood T, Klossner D. Collegiate ACL injury rates across 15 sports: national collegiate athletic association injury surveillance system data update (2004-2005 through 2012-2013). Clin J Sport Med 2016;26:518-23.

2 Gornitzky AL, Lott A, Yellin JL, et al. Sport-specific yearly risk and incidence of anterior cruciate ligament tears in high school athletes: a systematic review and meta-analysis. Am J Sports Med 2016;44:2716-23.

3 Joseph AM, Collins CL, Henke NM, et al. A multisport epidemiologic comparison of anterior cruciate ligament injuries in high school athletics. J Ath/ Train 2013;48:810-7.

4 Montalvo AM, Schneider DK, Yut L, et al. "What's my risk of sustaining an ACL injury while playing sports?" A systematic review with meta-analysis. Br I Sports Med 2019;53:1003-12.

5 Montalvo AM, Schneider DK, Webster KE, et al. Anterior cruciate ligament injury risk in sport: a systematic review and meta-analysis of injury incidence by sex and sport classification. J Athl Train 2019;54:472-82.

6 Elliot DL, Goldberg L, Kuehl KS. Young women's anterior cruciate ligament injuries. Sports Medicine 2010;40:367-76.

7 Hewett TE, Zazulak BT, Myer GD. Effects of the menstrual cycle on anterior cruciate ligament injury risk: a systematic review. Am J Sports Med 2007;35:659-68.

8 Ireland ML. The female ACL: why is it more prone to injury? Orthop Clin North Am 2002;33:637-51.

9 Khayambashi K, Ghoddosi N, Straub RK, et al. Hip muscle strength predicts noncontact anterior cruciate ligament injury in male and female athletes: a prospective study. Am J Sports Med 2016;44:355-61.

10 King AH, Krych AJ, Sousa PL, et al. Increased risk of second anterior cruciate ligament injury for female soccer players. Orthop J Sports Med 2015;3:2325967115S0011.

11 Levins JG, Argentieri EC, Sturnick DR, et al. Geometric characteristics of the knee are associated with a noncontact $\mathrm{ACL}$ injury to the contralateral knee after unilateral $\mathrm{ACL}$ injury in young female athletes. Am J Sports Med 2017;45:3223-32.

12 Malinzak RA, Colby SM, Kirkendall DT, et al. A comparison of knee joint motion patterns between men and women in selected athletic tasks. Clin Biomech 2001;16:438-45.

13 Powers CM. The influence of abnormal hip mechanics on knee injury: a biomechanical perspective. J Orthop Sports Phys Ther 2010;40:42-51.

14 Quatman CE, Hewett TE. The anterior cruciate ligament injury controversy: is "valgus collapse" a sex-specific mechanism? Br J Sports Med 2009;43:328-35.

15 Rozzi SL, Lephart SM, Gear WS, et al. Knee joint laxity and neuromuscular characteristics of male and female soccer and basketball players. Am I Sports Med 1999:27:312-9

16 Silvers HJ, Mandelbaum BR. Prevention of anterior cruciate ligament injury in the female athlete. Br I Sports Med 2007:41 Suppl 1:i52-9.

17 Wojtys EM, Huston LJ, Lindenfeld TN, et al. Association between the menstrual cycle and anterior cruciate ligament injuries in female athletes. Am I Sports Med 1998;26:614-9.

18 Zebis MK, Andersen LL, Bencke J, et al. Identification of athletes at future risk of anterior cruciate ligament ruptures by neuromuscular screening. Am I Sports Med 2009;37:1967-73.
19 Della Villa F, Buckthorpe M, Grassi A, et al. Systematic video analysis of ACL injuries in professional male football (soccer): injury mechanisms, situational patterns and biomechanics study on 134 consecutive cases. Br I Sports Med 2020;54:1423-32.

20 Webster KE, Hewett TE. Meta-Analysis of meta-analyses of anterior cruciate ligament injury reduction training programs. J Orthop Res 2018;36:2696-708.

21 Patterson B, Culvenor AG, Barton CJ, et al. Poor functional performance 1 year after $A C L$ reconstruction increases the risk of early osteoarthritis progression. Br I Sports Med 2020;54:546-55.

22 Whittaker JL, Roos EM. A pragmatic approach to prevent post-traumatic osteoarthritis after sport or exercise-related joint injury. Best Pract Res Clin Rheumatol 2019:33:158-71.

23 Whittaker JL, Toomey CM, Nettel-Aguirre A, et al. Health-related outcomes after a youth sport-related knee injury. Med Sci Sports Exerc 2019;51:255-63.

24 Webster KE, Feller JA. Expectations for return to preinjury sport before and after anterior cruciate ligament reconstruction. Am J Sports Med 2019;47:578-83.

25 Filbay SR, Ackerman IN, Russell TG, et al. Return to sport matters-longer-term quality of life after ACL reconstruction in people with knee difficulties. Scand I Med Sci Sports 2017; 27:514-24

26 Ardern CL, Taylor NF, Feller JA, et al. Fifty-five per cent return to competitive sport following anterior cruciate ligament reconstruction surgery: an updated systematic review and meta-analysis including aspects of physical functioning and contextual factors. Br J Sports Med 2014;48:1543-52.

27 Lai CCH, Ardern CL, Feller JA, et al. Eighty-three per cent of elite athletes return to preinjury sport after anterior cruciate ligament reconstruction: a systematic review with meta-analysis of return to sport rates, graft rupture rates and performance outcomes. Br J Sports Med 2018:52:128-38.

28 Wiggins AJ, Grandhi RK, Schneider DK, et al. Risk of secondary injury in younger athletes after anterior cruciate ligament reconstruction: a systematic review and meta-analysis. Am J Sports Med 2016;44:1861-76.

29 Paterno MV, Rauh MJ, Schmitt LC, et al. Incidence of contralateral and ipsilateral anterior cruciate ligament $(\mathrm{ACL})$ injury after primary $\mathrm{ACL}$ reconstruction and return to sport. Clin J Sport Med 2012;22:116-21.

30 Paterno MV, Rauh MJ, Schmitt LC, et al. Incidence of second ACL injuries 2 years after primary ACL reconstruction and return to sport. Am I Sports Med 2014;42:1567-73.

31 Maletis GB, Inacio MCS, Funahashi TT. Risk factors associated with revision and contralateral anterior cruciate ligament reconstructions in the Kaiser Permanente ACLR registry. Am J Sports Med 2015;43:641-7.

32 Snaebjörnsson T, Svantesson E, Sundemo D, et al. Young age and high BMI are predictors of early revision surgery after primary anterior cruciate ligament reconstruction: a cohort study from the Swedish and Norwegian knee ligament registries based on 30,747 patients. Knee Surg Sports Traumatol Arthrosc 2019;27:3583-91.

33 Kaeding CC, Pedroza AD, Reinke EK. Risk factors and predictors of subsequent ACL injury in either knee after $\mathrm{ACL}$ reconstruction: prospective analysis of 2488 primary ACL reconstructions from the moon cohort. Am J Sports Med 2015;43:1583-90.

34 Ekeland A, Engebretsen L, Fenstad AM, et al. Similar risk of ACL graft revision for alpine skiers, football and handball players: the graft revision rate is influenced by age and graft choice. Br J Sports Med 2020;54:33-7.

35 McPherson AL, Feller JA, Hewett TE, et al. Psychological readiness to return to sport is associated with second anterior cruciate ligament injuries. Am I Sports Med 2019;47:857-62.

36 Paterno MV, Huang B, Thomas S, et al. Clinical factors that predict a second ACL injury after $\mathrm{ACL}$ reconstruction and return to sport: preliminary development of a clinical decision algorithm. Orthop J Sports Med 2017;5:232596711774527.

37 Laboute E, Savalli L, Puig P, et al. Analysis of return to competition and repeat rupture for 298 anterior cruciate ligament reconstructions with patellar or hamstring tendon autograft in sportspeople. Ann Phys Rehabil Med 2010;53:598-614

38 Shelbourne KD, Sullivan AN, Bohard K, et al. Return to basketball and soccer after anterior cruciate ligament reconstruction in competitive school-aged athletes. Sports Health 2009:1:236-41.

39 Carolan D, King E, Richter C, et al. Differences in strength, patient-reported outcomes, and return-to-play rates between athletes with primary versus revision ACL reconstruction at 9 months after surgery. Orthop I Sports Med 2020:8:232596712095003

40 Cristiani R, Engström B, Edman G, et al. Revision anterior cruciate ligament reconstruction restores knee laxity but shows inferior functional knee outcome compared with primary reconstruction. Knee Surg Sports Traumatol Arthrosc 2019;27:137-45

41 Filbay SR, Grindem $\mathrm{H}$. Evidence-based recommendations for the management of anterior cruciate ligament (ACL) rupture. Best Pract Res Clin Rheumatol 2019:33:33-47.

42 Moher D. Corrigendum to: Preferred reporting items for systematic reviews and metaanalyses: the PRISMA statement. International Journal of Surgery 2010;8:336-341. Int J Surg 2010;8:658

43 Liberati Aet al. The PRISMA statement for reporting systematic reviews and meta-analyses of studies that evaluate health care interventions: explanation and elaboration. Ann Intern Med 2009;151:W-65-W-94. 
44 Shea BJ, Reeves BC, Wells G, et al. AMSTAR 2: a critical appraisal tool for systematic reviews that include randomised or non-randomised studies of healthcare interventions, or both. BMJ 2017;358:j4008.

45 Büttner F, Winters M, Delahunt E, et al. Identifying the 'incredible'! Part 1: assessing the risk of bias in outcomes included in systematic reviews. Br J Sports Med 2020;54:798-800.

46 Kim SY, Park JE, Lee YJ, et al. Testing a tool for assessing the risk of bias for nonrandomized studies showed moderate reliability and promising validity. J Clin Epidemiol 2013;66:408-14.

47 Sterne JA, Hernán MA, Reeves BC, et al. ROBINS-I: a tool for assessing risk of bias in non-randomised studies of interventions. BMJ 2016;355:i4919.

48 Atkins $D$, Best D, Briss PA, et al. Grading quality of evidence and strength of recommendations. BMJ 2004:328:1490.

49 Ryan R, HIII S. How to grade the quality of evidence: Cochrane Consumers and Communication Group, 2016. Available: https://colorectal.cochrane.org/sites/ colorectal.cochrane.org/files/public/uploads/how_to_grade.pdf

50 Weir A, Rabia S, Ardern C. Trusting systematic reviews and meta-analyses: all that glitters is not gold!: BMJ Publishing Group Ltd and British Association of Sport and Exercise Medicine, 2016

51 Celentano DD, Mhs S, Szklo M. Gordis. Epidemiología. Elsevier, 2019.

52 Nielsen RO, Bertelsen ML, Verhagen E, et al. When is a study result important for athletes, clinicians and team coaches/staff?: BMJ Publishing Group Ltd and British Association of Sport and Exercise Medicine, 2017.

53 Cordasco FA, Mayer SW, Green DW. All-inside, all-epiphyseal anterior cruciate ligament reconstruction in skeletally immature athletes: return to sport, incidence of second surgery, and 2-year clinical outcomes. Am J Sports Med 2017:45:856-63.

54 Demange MK, Camanho GL. Nonanatomic anterior cruciate ligament reconstruction with double-stranded semitendinosus grafts in children with open physes: minimum 15-year follow-up. Am J Sports Med 2014;42:2926-32.

55 Fleming BC, Fadale PD, Hulstyn MJ, et al. The effect of initial graft tension after anterior cruciate ligament reconstruction: a randomized clinical trial with 36-month follow-up. Am J Sports Med 2013:41:25-34.

56 Geffroy L, Lefevre N, Thevenin-Lemoine C, et al. Return to sport and re-tears after anterior cruciate ligament reconstruction in children and adolescents. Orthop Traumato/ Surg Res 2018:104:S183-8.

57 Graziano J, Chiaia T, de Mille P, et al. Return to sport for skeletally immature athletes after $\mathrm{ACL}$ reconstruction: preventing a second injury using a quality of movement assessment and quantitative measures to address modifiable risk factors. Orthop J Sports Med 2017:5:232596711770059.

58 Gupta R, Malhotra A, Sood M, et al. Is anterior cruciate ligament graft rupture (after successful anterior cruciate ligament reconstruction and return to sports) actually a graft failure or a re-injury? J Orthop Surg 2019;27:230949901982962.

59 Laboute E, Savalli L, Puig P, et al. Analysis of return to competition and repeat rupture for 298 anterior cruciate ligament reconstructions with patellar or hamstring tendon autograft in sportspeople. Ann Phys Rehabil Med 2010;53:598-614.

60 Bak K, Jørgensen U, Ekstrand J, et al. Reconstruction of anterior cruciate ligament deficient knees in soccer players with an iliotibial band autograft. a prospective study of 132 reconstructed knees followed for 4 (2-7) years. Scand J Med Sci Sports 2001;11:16-22.

61 Beischer S, Gustavsson L, Senorski EH, et al. Young athletes who return to sport before 9 months after anterior cruciate ligament reconstruction have a rate of new injury 7 times that of those who delay return. J Orthop Sports Phys Ther 2020:50:83-90.

62 Bourke HE, Salmon LJ, Waller A, et al. Survival of the anterior cruciate ligament graft and the contralateral $A C L$ at a minimum of 15 years. Am J Sports Med 2012;40:1985-92

63 Dekker TJ, Godin JA, Dale KM, et al. Return to sport after pediatric anterior cruciate ligament reconstruction and its effect on subsequent anterior cruciate ligament injury. I Bone Joint Surg 2017:99:897-904.

64 Everhart JS, Hughes L, Abouljoud MM, et al. Femoral nerve block at time of ACL reconstruction causes lasting quadriceps strength deficits and may increase shortterm risk of re-injury. Knee Surg Sports Traumatol Arthrosc 2020;28:1-7.
65 Heath EL, Salmon LJ, Cooper R, et al. 5-Year survival of pediatric anterior cruciate ligament reconstruction with living donor hamstring tendon grafts. Am J Sports Med 2019;47:41-51.

66 Heijne A, Hagströmer M, Werner S. A two- and five-year follow-up of clinical outcome after $\mathrm{ACL}$ reconstruction using BPTB or hamstring tendon grafts: a prospective intervention outcome study. Knee Surg Sports Traumatol Arthrosc 2015:23:799-807.

67 Kamath GV, Murphy T, Creighton RA, et al. Anterior cruciate ligament injury, return to play, and reinjury in the elite collegiate athlete: analysis of an NCAA division I cohort. Am J Sports Med 2014;42:1638-43.

68 Mohtadi N, Chan D, Barber R, et al. Reruptures, reinjuries, and revisions at a minimum 2-year follow-up: a randomized clinical trial comparing 3 graft types for $\mathrm{ACL}$ reconstruction. Clin J Sport Med 2016;26:96-107.

69 Webster KE, Feller JA. Clinical tests can be used to screen for second anterior cruciate ligament injury in younger patients who return to sport. Orthop I Sports Med 2019:7:232596711986300.

70 Nawasreh Z, Adams G, Pryzbylkowski O, et al. Influence of patient demographics and graft types on $\mathrm{ACL}$ second injury rates in ipsilateral versus contralateral knees: a systematic review and meta-analysis. Int J Sports Phys Ther 2018;13:561-74.

71 Walter SD, Holford TR. Additive, multiplicative, and other models for disease risks. Am J Epidemiol 1978;108:341-6.

72 Weinberg CR. Interaction and exposure modification: are we asking the right questions? Am J Epidemiol 2012;175:602-5.

73 Losciale JM, Zdeb RM, Ledbetter L, et al. The association between passing return-tosport criteria and second anterior cruciate ligament injury risk: a systematic review with meta-analysis. J Orthop Sports Phys Ther 2019;49:43-54.

74 Wellsandt E, Failla MJ, Snyder-Mackler L. Limb symmetry indexes can overestimate knee function after anterior cruciate ligament injury. J Orthop Sports Phys Ther 2017; 47:334-8.

75 Losciale JM, Bullock G, Cromwell C, et al. Hop testing lacks strong association with key outcome variables after primary anterior cruciate ligament reconstruction: a systematic review. Am J Sports Med 2020;48:036354651983879.

76 Gokeler A, Welling W, Benjaminse A, et al. A critical analysis of limb symmetry indices of hop tests in athletes after anterior cruciate ligament reconstruction: a case control study. Orthop Traumatol Surg Res 2017;103:947-51.

77 Andrade $R$, Pereira $R$, van Cingel $R$, et al. How should clinicians rehabilitate patients after $A C L$ reconstruction? A systematic review of clinical practice guidelines (CpGs) with a focus on quality appraisal (agree II). Br J Sports Med 2020;54:512-9.

78 Gokeler A, Welling W, Zaffagnini S, et al. Development of a test battery to enhance safe return to sports after anterior cruciate ligament reconstruction. Knee Surg Sports Traumatol Arthrosc 2017;25:192-9.

79 Welling W, Benjaminse A, Seil R, et al. Low rates of patients meeting return to sport criteria 9 months after anterior cruciate ligament reconstruction: a prospective longitudinal study. Knee Surg Sports Traumatol Arthrosc 2018:26:3636-44.

80 Sanders TL, Maradit Kremers H, Bryan AJ, et al. Incidence of anterior cruciate ligament tears and reconstruction. Am J Sports Med 2016;44:1502-7.

81 Schilaty ND, Nagelli C, Bates NA, et al. Incidence of second anterior cruciate ligament tears and identification of associated risk factors from 2001 to 2010 using a geographic database. Orthop J Sports Med 2017:5:232596711772419.

82 Zacharias AJ, Whitaker JR, Collofello BS, et al. Secondary injuries after pediatric anterior cruciate ligament reconstruction: a systematic review with quantitative analysis. Am J Sports Med 2021;49:1086-93.

83 Grindem $\mathrm{H}$, Engebretsen L, Axe M, et al. Activity and functional readiness, not age, are the critical factors for second anterior cruciate ligament injury — the Delaware-Oslo ACL cohort study. Br J Sports Med 2020;54:1099-102.

84 Schulz KF, Altman DG, Moher D, et al. Consort 2010 statement: updated quidelines for reporting parallel group randomised trials. BMJ 2010;340:C332.

85 Svantesson E, Hamrin Senorski E, Webster KE, et al. Clinical outcomes after anterior cruciate ligament injury: Panther symposium ACL injury clinical outcomes consensus group. Orthop J Sports Med 2020:8:232596712093475.

86 von Elm E, Altman DG, Egger M, et al. The strengthening the reporting of observational studies in epidemiology (STROBE) statement: guidelines for reporting observational studies. Ann Intern Med 2007;147:573-7. 